\title{
Alterations of Hematological and Biochemical Profile of Calves Infected Naturally with Tropical Theileriosis
}

\author{
Abubakar AS ${ }^{1}$, El Hussein AM${ }^{1}$, Abdelsalam MA ${ }^{2}$, Salih DA $^{1}$, Samia HA ${ }^{1}$, Hala Elrayah ${ }^{1}$ and Sara \\ $\mathrm{AM}^{1 *}$ \\ ${ }^{1}$ Central veterinary research laboratory, Sudan \\ ${ }^{2}$ Sudan University of Science and Technology \\ *Corresponding author: Sara A Mohamed, Assistant professor, Central veterinary research laboratory, Sudan \\ To Cite This Article: Hala Elrayah and Sara AM. Alterations of Hematological and Biochemical Profile of Calves Infected Naturally with Tropical \\ Theileriosis. Am J Biomed Sci \& Res. 2019 - 5(3). AJBSR.MS.ID.000915. DOI: 10.34297/AJBSR.2019.05.000915.
}

Received: 眥 September 13, 2019; Published: 眥 September 25, 2019

Abstract

Background: Bovine theileriosis in cattle is a disease caused by protozoan parasite known as Theileria annulata, transmitted by ticks of genus Hyalomma. More than 250 million domestic cattle have been estimated to be at risk. This disease leads to severe losses in production and reproduction of cattle. The present study is performed to investigate the effect of Theileriosis on serum hematological and biochemical profile of calves, as a supportive aid tool for diagnosis of the disease and to figure out any kind of symptomatic treatment to support animal health to reach complete recovery.

Materials and Methods: 30 crossbred, 3 months age average Calves were purchased from Keynana company (White Nile state), prior to purchase they were tested for thieleriosis, blood samples were collected and screened by blood smear and confirmed by IFAT, and finally by PCR. Calves were moved to Khartoum state and allocated in a farm recorded positive theileriosis infections previously with noticeable presence of ticks. Samples collected in a period started from January to March 2016 depending on appearance of high body temperature $\left(40^{\circ} \mathrm{C}\right)$, enlargement of lymph nodes and any other sign or symptom related. Samples were tested as described before.

Results: Positive samples showed pronounced reduction in Hb, PCV, and RBCs, WBCs count 10.1 $\pm 0.75,27.6 \pm 2.8,6.0 \pm 2.3$ and $2.7 \pm 1.2$ respectively. While the biochemical profile revealed significant low level of serum total protein, albumin and phosphorus. Whereas liver enzymes elevated significantly, ALT, AST, GGT 53.2 \pm 8.9 , total bilirubin $4.6 \pm 0.08$ and direct bilirubin $4.3 \pm 0.12$. While creatinine, and glucose values, were not significantly different between pre and post infection.

Conclusion: Hematological and biochemical profile of calves after theileriosis infection was tremendously influenced, so it could be a considerable tool for tentative diagnosis of tropical theileriosis (Figure 1).

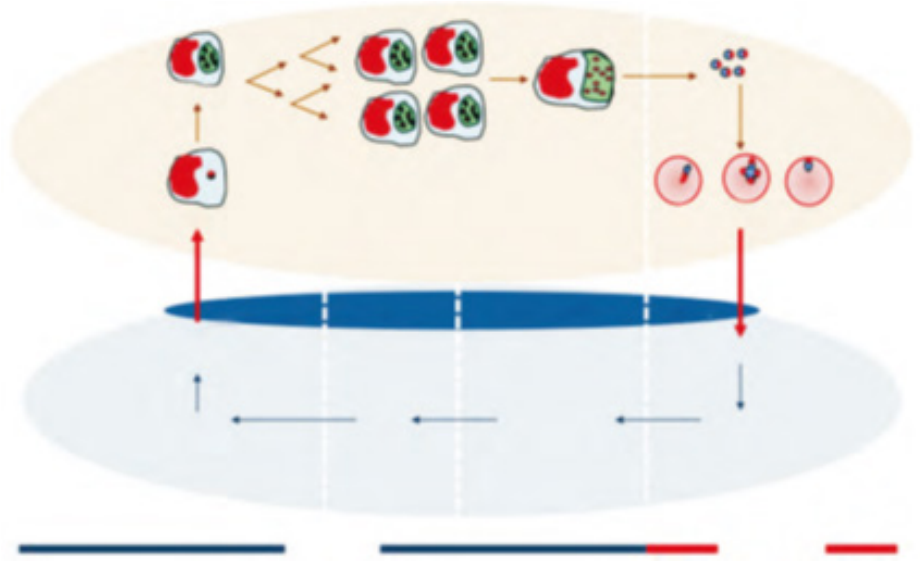

Figure 1

Keywords: Calves; Theileriosis; Biochemical profile; Crossbred; Bilirubin; Total protein; Phosphorus

Abbreviations: GGT: Gamma Glutamyl Transferase; AST: Aspartate Aminotransferase; ALT: Alanine Transaminase; PCR: Polymerase Chain Reaction; WBCs: White Blood Cells; RBCs: Red Blood Cells; IFAT: Indirect Immunofluorescent Antibody Test; MCV: Mean Corpuscular Volume; MCH: Mean Corpuscular Hemoglobin; MCHC: Mean Corpuscular Hemoglobin Concentration; FID: Flame Ionization Detector; PCV: Packed Cell Volume 


\section{Introduction}

Tropical Thieleriosis is one of the most concerning Tick-Borne Diseases (TBD) of cattle prevailing in northern Sudan [1] The wide allocation of TBD throughout the world especially in tropical and sub-tropical district embrace Sudan [2]. Tropical theileriosis is caused by T. annulata and transmitted by Ixodid ticks of genus Hyalomma; after cyclical development in the vector [3]. The disease is highly endemic in some regions of Sudan, where it considered fatal in forgin and crossbred animals. The mortality in local breed animals is little or not exist at all; with almost no clinical signs or symptoms except in animals under environmental, nutritional or any other kind of stress [4]. Tropical theileriosis plays a crucial role in livestock production loss in Sudan; hence it considered as one of the most economically imposing diseases [5]. Sporozoite; is the form in which the theileria parasite introduced to the host body during the procedure of tick feeding. Straight entrance of the sporozoite into the leukocytes is then occur, where they get mature into macro schizont, the macro schizont evolve further into micro schizont and eventually into merozoites. These merozoites invade the RBCs and develop into piroplasm.

The cardinal symptoms shown by affected cattle are, high fever and lingering anemia because of the intraerythrocytic parasitism [6]. Other pivotal clinical symptoms include, weight loss, anorexia, petechial hemorrhage and general weakness [7]. Laboratory tests are vital auxiliary tools to evaluate the animal health condition. Sero-biochemical and hematological perversions is a prediction factors for evaluating the severity of the disease, helpful tool for diagnosis and reveal the prospect of disease prognosis [8,9]. Biochemical analyses of blood serum are very useful to get an insight in the metabolic and health status of animals. During diagnostic procedure it is very useful to compare the values obtained from ill animals with normal values in healthy animals. The majority of biochemical parameters in young animals differ from normal values for adults. These values are changing with the age [8]. The efficacy of specific organ's function could be revealed throughout shedding a light on serum biochemical profile, serum biochemical profile values can reflect the prognosis of the disease, which eventually provide suitable therapeutic protocols towards most favorable clinical outcome [4].

Plasma biochemistry may be an indication of the severity of the infection, and a very good tool for diagnosis and evaluation of the therapy applied. Also, to understand the host-parasite relationship at a molecular level and to describe the disease clearly, some biochemical parameters may be determined based on the above considerations [10]. The present study was designed to investigate the impact of the tropical theileriosis on some serum components associated with protein, and carbohydrate metabolism in calves naturally infected with T. annulata.

\section{Ethical Approve}

The ethical approve document was obtained from Sudanese
Veterinary Council, Khartoum-Sudan.

\section{Materials and Methods}

\section{Animals, site and duration of trial}

The experiment duration is 5 months; extended from November-2016 to March-2017. 30 male calves, crossbred, 3-6 months age were brought from keynana Company, which exists in the middle of Sudan- (White Nile state)-tick controlled area. Calves moved to eastern Khartoum state, and allocated in a farm with history records of theileriosis infection and mortality, tick manifestation was clearly noticeable in the farms. Claves were put under hay feeding with add libtium reach to water supply.

\section{Samples collection}

Prior to purchase blood samples were collected in plain and EDTA coated tubes. Samples screened for theileria using blood smear, then confirmed by IFAT and PCR, respectively to guarantee they are theileriosis free. Biochemical and hematological profile were determined as well. After appearance of clinical signs, blood samples were collected again, and the same tests mentioned above were done.

\section{Hematology and serum analysis \\ Blood heamogram}

Blood samples were collected from jugular vein using $5 \mathrm{ml}$ disposable syringe into clean dry bottles containing the disodium salt of ethylene diamine tetra acetic acid (EDTA) as anticoagulant for hematological samples; which were evaluated on the same day of collection. Blood was analyzed for hemoglobin ( $\mathrm{Hb}$ ) concentration, red blood cells count (RBCs), packed cell volume (PCV) and white blood cell count (WBCs), according to methods described by [11]. $\mathrm{MCV}, \mathrm{MCH}$ and $\mathrm{MCHC}$ values were calculated according to equation described by

\section{$\mathrm{MCV}=\mathrm{PCV} / \mathrm{RBCs}$ count. \\ $\mathrm{MCH}=\mathrm{Hb} / \mathrm{RBCs}$ count. \\ $\mathrm{MCHC}=\mathrm{Hb} / \mathrm{PCV}$.}

\section{Biochemical profile}

A commercially available kit (Biosystem Laboratory Products LTD, Spain) was used to measure different serum biochemical parameters, following the instructions of manufacturer.

\section{Statistical analysis}

The data thus generated were subjected to un-paired t-test to compare the difference of hematological and biochemical parameters at $\mathrm{P} \leq 0.05$.

\section{Results and Discussion}

Twelve calves out of thirty were infected with theileriosis (prevalence percentage 40\%), nine infected calves died with mor- 
tality rate (30\%) (Figure 2). Infection with theileriosis caused significant reduction ( $\mathrm{p} \leq 0.05$ ) of WBCs, RBCs, Hb, PCV, MCV and MCHC (Table 1), compared to the values recorded before infection. MCH, recorded pronounced elevation after infection. Serum biochemical profile showed significant low total protein, albumin, globulin, AST, ALT, GGT, D. Bilirubin, Glucose and Phosphorus in diseased animals (Figure 3). Creatinine, Urea and Calcium revealed no significant different values before and after infection (Table 2).
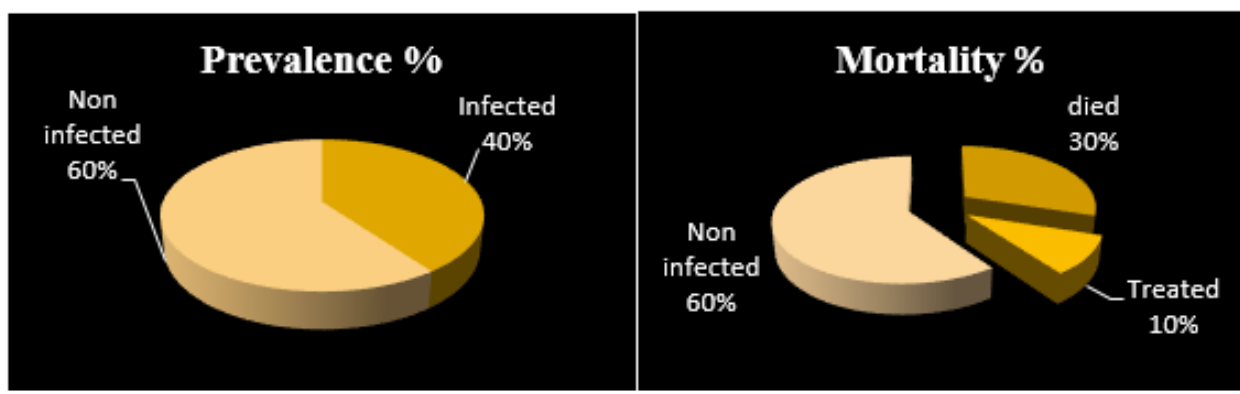

Figure 2: Prevalence and mortality incidence (\%).

Table 1: Blood values parameters pre and post infection.

\begin{tabular}{|c|c|c|c|c|c|c|c|}
\hline \multirow{2}{*}{ Group } & \multirow{2}{*}{ WBCs $10^{3} / \mu \mathrm{l}$} & RBCs & $\mathbf{H b}$ & PCV & MCV & MCH & МCHC \\
\hline & & $10^{6} / \mu \mathrm{l}$ & $\mathrm{g} / \mathrm{dl}$ & $\%$ & fl & pg & $\%$ \\
\hline Pre infection $\mathrm{n}=30$ & $7.3 \star \pm 1.2$ & $8.1 \star \pm 2.3$ & $16.2 \star \pm 0.75$ & $49.2 \star \pm 2.8$ & $38.7 \star \pm 6.5$ & $17.8 \star \pm 2.8$ & $34.6 \star \pm 0.89$ \\
\hline Post infection $\mathrm{n}=12$ & $2.7 \pm 1.2$ & $6.0 \pm 2.3$ & $10.1 \pm 0.75$ & $27.6 \pm 2.8$ & $57.6 \pm 6.5$ & $20.4 \pm 2.8$ & $30.3 \pm 0.89$ \\
\hline P-value & 0.05 & 0.04 & 0.01 & 0.01 & 0.05 & 0.05 & 0.05 \\
\hline
\end{tabular}

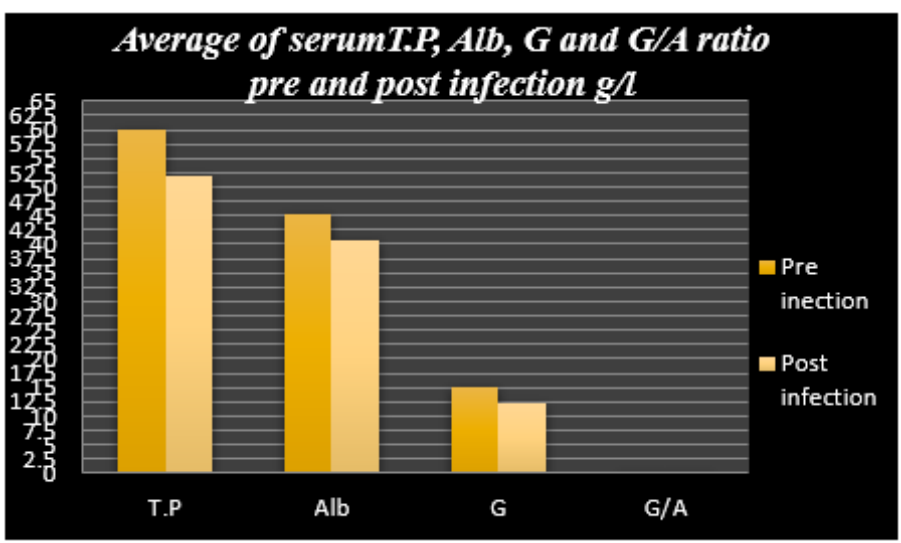

Figure 3: Average of serum T.P, Alb, G and G/A ratio pre and post infection g/l.

T P: Total Protein; Alb: Albumin; G: Globulin; G/Alb: Globulin/Albumin

\section{Hematology results}

The results obtained from hematologic investigation revealed significant reduction in RBCs, WBCs, $\mathrm{Hb}$ and PCV Values were 6.0 x $10^{6} / \mu \mathrm{l}, 2.7 \times 10^{6} / \mu \mathrm{l}, 10.1 \mathrm{~g} / \mathrm{dl}$ and $27.6 \%$ respectively (Table 1 ), this result are in accordance with reported previously by [12] in cattle infected with theileriosis. Imtiaz and his coworkers reported a similar result also (6). Alteration in RBCs picture could be due to destructive parasite's influence on RBCs, or because of lytic effect of intra erythrocyte parasite [13], immune-mediated mechanism such as erythrophagocytosis might be responsible RBCs count reduction eventually. Anemia proposed to be resulted from removal of piroplasm from infected erythrocytes by macrophages. Oxygen free radicals could be another causative factor of anemia. An elevation of PCV values in infected animals [6]. MCV and MCHC followed the same trend and recorded significant low values in diseased animals compared to pre infection status. Currently the MCH values were significantly higher after infection occurred. These observations were recorded formerly by [14].

\section{Serum biochemical profile results}

\section{liver enzymes}

Serum ALT and AST, concentrations are indicators of liver function. ALT and AST, serum values were elevated significantly after infection; values were 62.8 and 99.4IU/L respectively (Table 2). This elevation could be attributed to macular degeneration; as a result of prolonged recumbency due to theileriosis. Hepatic dysfunction may also be caused by the inflammatory status; which caused by trapping the damaged infected RBCs, and lymphocytes. These findings are in agreement with [15]; who reported elevation of mentioned enzymes in cattle infected with tropical theileriosis. In regard to 
GGT levels, our current result is contrary to some previous studies and in agreement with others; hence Ali and his coworker's high serum level of GGT in infected cattle compared to healthy ones. Similarly; this study showed significant elevation of serum GGT con- centration too (Table 2), while Campbell and his team reported no significant different levels of the enzymes in serum of infected and healthy animals.

\begin{tabular}{|c|c|c|c|}
\hline Table 2: Blood values parameters pre and post infection. & Post infection $\mathbf{n = 1 2}$ & P-value \\
\hline Parameter & Pre infection $\mathbf{n = 3 0}$ & $99.4^{\mathrm{a}} \pm 8.5$ & 0.005 \\
\hline AST IU/L & $72.2^{\mathrm{b}} \pm 8.5$ & $62.8^{\mathrm{a}} \pm 8.9$ & 0.001 \\
\hline ALT IU/L & $41.6^{\mathrm{b}} \pm 8.9$ & $53.2^{\mathrm{a}} \pm 8.5$ & 0.001 \\
\hline GGT IU/L & $30.6^{\mathrm{b}} \pm 8.5$ & $51.9^{\mathrm{b}} \pm 6.9$ & 0.001 \\
\hline Total protein g/L & $60.05^{\mathrm{a}} \pm 6.9$ & $40.8^{\mathrm{b}} \pm 3.9$ & 0.001 \\
\hline Albumin g/L & $45.4^{\mathrm{a}} \pm 3.9$ & $12.1 \pm 3.7$ & 0.09 \\
\hline globulin g/L & $14.9 \pm 3.7$ & $7.6 \pm 1.6$ & 0.1 \\
\hline Calcium mg/dl & $8.69 \pm 1.6$ & $5.5^{\mathrm{b}} \pm 1.7$ & 0.004 \\
\hline Phosphorus mg/dl & $7.3 \mathrm{a} \pm 1.7$ & $46.0 \pm 5.6$ & 0.1 \\
\hline Urea mg/dl & $36.3 \pm 5.6$ & $4.6^{\mathrm{a}} \pm 0.08$ & 0.05 \\
\hline $\begin{array}{c}\text { Total Bilirubin } \\
\text { mg/dl }\end{array}$ & $3.7 \mathrm{~b} \pm 0.08$ & $4.3^{\mathrm{a}} \pm 0.12$ & 0.005 \\
\hline $\begin{array}{c}\text { Direct Bilirubin } \\
\text { mg/dl }\end{array}$ & $3.8 \mathrm{~b} \pm 0.12$ & $73.4 \mathrm{~b} \pm 3.5$ & 0.01 \\
\hline Glucose mg/dl & $101.3 \mathrm{a} \pm 3.5$ & $0.19 \mathrm{a} \pm 0.04$ & 0.1 \\
\hline Creatinine mg/dl & $0.09 \mathrm{~b} \pm 0.04$ & $0.29 \pm 0.09$ & 0.3 \\
\hline G/A & $0.32 \pm 0.09$ & & \\
\hline
\end{tabular}

\section{Total protein and Albumin}

In the current study the observations about T.P, Alb and globulin levels recorded a significant decrease in infected animals (51.9, 40.8 and $12.1 \mathrm{~g} / \mathrm{l}$ respectively) in a comparison with pre infection values $(60.5,45.4$ and $14.9 \mathrm{~g} / \mathrm{l})$, (Table 2$)$. These findings are in line with reports of, Col and his team [12], and [6]. Who reported hypoproteinemia and hypo albuminemia. The reduction of serum protein level could be attributed to extra-vascular proteinaceous fluid in body cavities due to infected lymph nodes, resulting in edema [16].

The alteration of protein picture in animals after infection could be referred to decrease in protein synthesis as a consequence of anorexia and fever accompanied with theileria spp infection [17]. Two previous studies by Hassan [18], and Omer [19], reported that infection by theileria parasite has harmful influence on hepatocytes; leading to disturbed hepatic function such as decrease in albumin synthesis accompanied with increase in albumin catabolism.

\section{Bilirubin}

The present study reported significant raise of serum bilirubin levels after infection $4.6 \mathrm{mg} / \mathrm{dl}$ (Table 2), this might be due to increased destruction of parasitized RBCs by erythro phagocytosis in spleen, lymph nodes and other organs of reticuloenothelial system, or it might be caused by hepatic dysfunction and hemolytic anemia. These findings are in accordance with Imtiaz [6]and Jozica and Martina [8].

\section{Glucose}

Our present result revealed a significant decrease of serum glucose level after infection $73.4 \mathrm{mg} / \mathrm{dl}$; (Table 2); this result could be justified by proposing utilization of glucose by theileria parasite [20]. Continuous fever and metabolic disturbance could be reasons behind that glucose reduction after infection [12].

\section{Calcium and phosphorus}

Though serum calcium level was lower after infection occurred $(7.6 \mathrm{mg} / \mathrm{dl})$, but the difference was not significant compared to pre infection levels (Table 2). This result disagrees with the findings of Imtiaz, who reported significant decrease in calcium concentrations in crossbred cattle infected with bovine theileriosis. On the other hand, our findings showed significant decrease of serum phosphorus level post infection $(5.5 \mathrm{mg} / \mathrm{dl})$; this could be due to diarrhea or renal wasting. The current finding is in line with observations reported by Mahmoud H [21], and Imtiaz et al. [6] another synergetic finding by [22]; reported no significant different level of serum calcium was detected in animals infected with theileriosis.

\section{Creatinine and Urea}

Creatinine and urea concentrations; were not significantly affect after infection, though the pre infection levels of both were lower (0.09 and $36.3 \mathrm{mg} / \mathrm{dl})$, than post infection levels (0.19 and 46.0 $\mathrm{mg} / \mathrm{dl}$ ); but there was no significant difference at $\mathrm{p} \leq 0.05$. These results disagree with the findings of Denizhan et al. [23], who reported significant elevation in serum creatinine levels in cattle in- 
fected with theileriosis. On another hand the present findings about serum urea levels were similar to those reported by Omer and his team [22], no significant difference of serum urea level between pre and post infection. Present results and Omer et al results are in accordance with the findings of Singh et al. [24] and Denizhan et al. [25].

\section{Conclusion}

The massive alteration of hematological and biochemical profile of calves infected by theileriosis; demonstrates the potency of this disease to damage different animal body's systems; leading to metabolic disturbances incorporates together and increase the severity of the disease. Monitoring biochemical profile of infected animals may help improving treatment protocol, when to make approaches to compensate any minerals, glucose, etc. deficiency; as a supportive treatment beside the principle medication to fulfill the need for fast recovery of the infected animals.

\section{Research Highlights}

1) Preparing the experimental site.

2) Purchase calves.

3) Performing the trial and follow up the progress of infection.

4) Samples collection and preservation.

5) Determination of blood biochemical profile.

\section{Limitations}

Reagents and buffers are hard to found because of poor availability and expensive prices. Beside the obstacle high experimental animals' cost.

\section{Recommendation}

This study discovered that every experiment has its own results depending on various factors including environmental and physiological ones, which can be beneficial for evaluating each case individually in order to provide a symptomatic treatment support the sick animal throughout the course of treatment by reducing the effect of deficiency of some nutrients. this study will help the researchers to uncover the critical areas of importance of serum biochemical profile in sustaining the animal condition until complete recovery.

\section{Authors' Contribution and Competing Interests}

1) Corresponding author: write the manuscript.

2) $1^{\text {st }}$ and sixth Author: performing the experiment and analysis of samples.

3) $2^{\text {nd }}, 3^{\text {rd }}, 4^{\text {th }}$ and $5^{\text {th }}$ Authors, follow up, correction.

\section{References}

1. FAO (1983b) Ticks and tick-borne Diseases control. The Sudan: Studies on important tick-borne diseases of cattle, Technical report No 2, AG: CP/SUD/024/DEN, Rome.
2. Jongejan F, G Uilenberg (2004) The Global importance of ticks. Parasitology 129: 3-14.

3. Uilenberg G (1981) Theileria infections other than east coast fever. Curr Top Vet Med Anim Sci 6: 411-427.

4. Salih DA, Sharieff OE, Lazarus AG, Hassan SM, El Hussein AM (2005) Natural infection rates and transmission of Theileria annulata by Hyalomma anatolicum anatolicum ticks in the Sudan. Onderstepoort J Vet Res 72(4): 303-307.

5. Sharieff OE, Hassan SM, Salih DA, El Hussein AM (2017) Attenuation of two Field Isolates of Theileria Annulata and their Potential as Vaccine Candidates against Tropical Theileriosis in the Sudan. International Journal of Scientific Research in Science, Engineering and Technology 3(1): 54-58.

6. Khan IA, Khan A, Hussain A, Riaz A, Aziz A (2011) Hemato-Biochemical Alterations in Cross Bred Cattle Affected with Bovine Theileriosis in Semi Arid Zone. Pak Vet J 31(2): 137-140.

7. El-Deeb WM and EE Younis (2009) Clinical and biochemical studies on Theileria annulata in Egyptian buffaloes (Bubalus bubalis) with particular orientation to oxidative stress and ketosis relationship. Vet Parasitol 164: 301-305.

8. Jozica Jezek, Marijaklopcic, and Martina Klinkon (2006) Influence of age on biochemical parameters in calves. Bull Vet Inst Pulawy 50: 211-214.

9. DV Modi, CM Bhadesiya, GC Mandali (2014) Serum Biochemistry Alterations in Theileriosis Affected Crossbred Cows in Banaskantha District of Gujarat. International Journal of Novel Research in Healthcare and Nursing 1(1): 12-14.

10. Ramazan Col, AND Ugur Uslu (2007) changes in selected serum components in cattle naturally infected with theileria annulata. Bull Vet Inst Pulawy 51: 15-18.

11. Habibzadeh F, Yadollahie M, Roshanipoor M, Haghshenas M (2001) Derivation of blood hemoglobin concentration from hematocrit: A simple method for rural areas 4(3): 120-122.

12. Col R, U Uslu (2007) Changes in selected serum components in cattle naturally infected with Theileria annulata. Bull Vet Inst Pulawy 51: 1518.

13. Nazifi S, SM Razavi, M Reiszadeh, Z Esmailnezhad, M Ansari-Lari (2010) Diagnostic values of acute phase proteins in Iranian indigenous cattle infected with Theileria annulata. Vet arhiv 80: 205-214.

14. Turgeon and Mary Louis (1999) Clinical hematology-theories and procedures. ( $\left.3^{\text {rd }} \mathrm{edn}\right)$, Lippincott wilkins, USA.

15. Alam TH, Nasr SM (2011) Hematological and Biochemical investigation in bovine babesiosis and theileriosis. Benha Veterinary Medical Journal 22(2): 118-126.

16. Homer M, Aguilar I, Persing D (2000) Babesiosis. Clin Microb Rev 13(3): 451-469.

17. Tehrani AA, Hosseini E, Bahrami AM (2013) Biochemical, Hematological studies in cattle naturally infected with Theileria annulata. Bull Env Pharmacol Life Sci 2(9): 7-10.

18. Osman S, Al-Gabary M (2007) Clinical, haematological and therapeutic studies on tropical theileriosis in water buffaloes in Egypt. Vet Parasit 146: $37-45$

19. Stockham S, Kjemtrup A, Cuddihee P (2000) Theileriosis in a Missouri beef herd caused by Theileria buffeli case report, herd investigation, ultrastructure, phylogenetic analysis, and experimental transmission. Vet. Path. 37(1): 11-21.

20. Kaneko J (1997) Serum Proteins and Dysproteinemias. In: J Kaneko et al. (Eds.), Clinical Biochemistry of Domestic Animals. ( $5^{\text {th }}$ edn). Academic Press, Bruss, pp. 117-138.

21. Mahmoud H, Ismail M, Rady A, Adham K (1990) Effect of dexametha-zone on protein fractions and erythrocytic antioxidant enzymes and lipid per- 
oxidation in Fasciola infested caws. Egypt J App Sci 5: 433- 445.

22. Goyal P, ChaharA, RK Tanwar, Fakhruddin, SS Soni (2018) Serum Biochemical Study to Cattle-calves naturally infected with Theileria annulata Confirmed by Nested Polymerase Chain Reaction in Bikaner District of Rajasthan, India. Int J Curr Microbiol App Sci 7(2): 2927-2932.

23. Omer O, El-Malik K, Magzoub M, Mahmoud M, Haroun E, et al. (2003) Biochemical profiles in friesian cattle naturally infected with Theileria annulata in Saudi Arabia. Vet Res Commun 27: 15-25.
24. Somu YP, Mani S, Muthusamy RK, Mani S, Arul Kumar T, et al. (2017) Haemato- Biochemical and Electrolyte Alterations in Naturally Occurring Theileria Associated Bovine Anaemia (Taba). Journal of Animal Health and Production 5(2): 64-67.

25. Denızhan V, Kozat S, Ozkan C (2016) Evaluation of Cobalt, Vitamin B12 and Homocystein levels in Cattle infected with Theileria annulata. Journal of Livestock Science 8: 72-76. 